Terr. Atmos. Ocean. Sci., Vol. 18, No. 2, 379-393, June 2007

\title{
Preliminary Results of Stress Measurement Using Drill Cores of TCDP Hole-A: an Application of Anelastic Strain Recovery Method to Three-Dimensional In-Situ Stress Determination
}

\author{
Weiren Lin ${ }^{1, *}$, En-Chao Yeh ${ }^{1,5}$, Hisao Ito ${ }^{2}$, Tetsuro Hirono ${ }^{1,3}$, Wonn Soh ${ }^{1}$, \\ Chien-Ying Wang ${ }^{4}$, Kuo-Fong Ma ${ }^{4}$, Jih-Hao Hung ${ }^{4}$, and Sheng-Rong Song 5
}

(Manuscript received 18 January 2006, in final form 15 January 2007)

\begin{abstract}
In order to understand the feature of rock stress change at different depths above, within, and beneath the Chelungpu fault after the Chi-Chi earthquake, we employed a core-based stress measurement method, anelastic strain recovery (ASR) technique to determine both the orientations and magnitudes of present three-dimensional principal rock stresses using drill core samples retrieved from Taiwan Chelungpu-fault Drilling Project (TCDP) main Hole-A. The core samples used were taken from three depths; and their lithology were sandstone at depths of 592 and $1755 \mathrm{~m}$ and siltstone at $1112 \mathrm{~m}$. The anelastic strains of the specimens in nine directions, including six independent directions, were measured after its in-situ stress was released. Acquired anelastic strains were of high quality and reached several hundred microstrains, which is sufficiently high for the accuracy of the measurement system used. Thus, the strain data could be used for three-
\end{abstract}

\footnotetext{
${ }^{1}$ Kochi Institute for Core Sample Research, Japan Agency for Marine-Earth Science and Technology, Kochi, Japan

${ }^{2}$ Center for Deep Earth Exploration, Japan Agency for Marine-Earth Science and Technology, Yokohama, Japan

${ }^{3}$ Department of Earth and Space Science, Graduate School of Science, Osaka University, Toyonaka, Japan

${ }^{4}$ Department of Earth Sciences and Institute of Geophysics, National Central University, Chung-Li, Taiwan, ROC

${ }^{5}$ Department of Geosciences, National Taiwan University, Taipei, Taiwan, ROC

* Corresponding author address: Dr. Weiren Lin, Kochi Institute for Core Sample Research, Japan Agency for Marine-Earth Science and Technology, Kochi, Japan; E-mail: lin@jamstec.go.jp doi: 10.3319/TAO.2007.18.2.379(TCDP)
} 
dimensional analysis resulting in the determination of orientations and the estimation of magnitudes of the principal in-situ stresses. Preliminary stress measurement results showed that the orientations of principal stresses changed between the shallower depth above the fault and the deeper depth beneath it, that is, the present stress distribution in the TCDP hole might be influenced by the Chelungpu fault rupture. At the same time, anelastic strain recovery measurement is well suited for the task of directly determining the orientations of principal in-situ stresses and to estimate the magnitude of stresses at large/great depth.

\section{(Key words: Stress measurement, Anelastic strain recovery, Core-based method, Chelungpu fault, Taiwan Chelungpu-fault Drilling Project)}

\section{INTRODUCTION}

The 1999 Chi-Chi, Taiwan earthquake $\left(\mathrm{M}_{\mathrm{w}}\right.$ 7.6) produced spectacular surface faulting with vertical displacements of up to $8 \mathrm{~m}$ on the Chelungpu fault (Ma et al. 2000; Kao and Chen 2000). In order to resolve issues relating to the mechanism of earthquake generation and the mysterious rupture propagation of the fault, Taiwan Chelungpu-fault Drilling Project (TCDP) was undertaken (Mori et al. 2002). One of the main scientific goals of the TCDP is to determine in-situ stress states in the hanging wall, the vicinity, and footwall of the Chi-Chi earthquake rupture.

Unfortunately, there is no foolproof method by which magnitudes and orientations of three-dimensional in-situ stress can be reliably measured at large/great depth, although various field and laboratory measurement techniques have been proposed. In the case of a scientific deep drilling project, we suggest that a combined application of borehole method(s) and corebased method(s) be employed. As one of them, a simple and inexpensive method to determine in-situ stress from anelastic strain recovery (ASR) measurement of oriented cores can be considered as having a relatively explicit theoretical basis in comparison to other core-based methods. Originally, this method, firstly proposed by Voight (1968) and then developed by Teufel (1983), was based on the assumption that vertical stress is one of the three principal stresses, and only two-dimensional measurement was conducted. Subsequently, this method was theoretically extended to a three-dimensional version by Matsuki (1991). However, the three-dimensional method has found little practical application (Matsuki and Takeuchi 1993; Lin et al. 2006).

The present study has two aims. First, our scientific goal is to obtain the complete stress tensor at various depths located above, within, and beneath the Chelungpu fault. The second aim is technical. It is to verify whether the ASR method in three-dimensions can be applied for determining the in-situ stresses at large/great depth in a scientific drilling project and to acquire skills in sample preparation and application of appropriate measurement techniques. In this paper, the outline of the ASR method and its experimental techniques for determining the three-dimensional in-situ stress will be described. Next, we will present the preliminary re- 
sults of a case study where the ASR method was applied to three core samples retrieved from a depth range of about $600-1800 \mathrm{~m}$ in TCDP main Hole-A to determine the orientations and to estimate the magnitude of three-dimensional principal in-situ stress.

\section{ASR METHOD AND EXPERIMENTAL TECHNIQUES}

\subsection{Outline of ASR Method}

As mentioned above, Matsuki (1991) proposed a method for determining three-dimensional in-situ stresses based on the ASR measurements. For an isotropic viscoelastic material, when the in-situ stresses and the pore pressure are released stepwise at time $t=0$, the recovery behavior of viscoelastic deformation should consist of two independent modes; shear and volumetric deformation modes. Anelastic strain recovery compliances of the shear and volumetric deformation modes for elapsed time $t, \operatorname{Jas}(t)$ and $\operatorname{Jav}(t)$, respectively, are defined as follows:

$$
\begin{aligned}
& e_{i j}(t)=\operatorname{Jas}(t) S_{i j}, \\
& e_{m}(t)=\operatorname{Jav}(t)\left(\sigma_{\mathrm{m}}-\mathrm{p}_{0}\right),
\end{aligned}
$$

where $\sigma_{m}$ and $S_{i j}$ are released mean normal stress and stress deviation, respectively; $e_{m}(t)$ and $e_{i j}(t)$ are anelastic mean normal strain and anelastic strain deviation, respectively; and $p_{0}$ is pore pressure.

By applying the correspondence principle of linear viscoelastisity and making the assumption that the bulk modulus of the rock matrix is not a viscoelastic parameter, anelastic normal strain $\varepsilon_{a}(t)$ recovered during the time from 0 to $t$ in an arbitrary direction, the direction cosines of which are defined as $l, m, n$ with respect to $\mathrm{X}, \mathrm{Y}, \mathrm{Z}$ axes, is given by the following equation (Matsuki 1991; Matsuki and Takeuchi 1993):

$$
\begin{aligned}
\varepsilon_{a}(t)= & (1 / 3)\left[3 l^{2}-1\right) \sigma_{x}+\left(3 m^{2}-1\right) \sigma_{y}+\left(3 n^{2}-1\right) \sigma_{z} \\
& \left.+6 \operatorname{lm} \tau_{x y}+6 m n \tau_{y z}+6 n l \tau_{z x}\right] \operatorname{Jas}(t)+\left(\sigma_{m}-p_{0}\right) \operatorname{Jav}(t),
\end{aligned}
$$

where $\sigma_{x}, \sigma_{y}, \sigma_{z}, \tau_{x y}, \tau_{y z}$, and $\tau_{z x}$ are components of in-situ stress tensor. It should be noted that the thermal expansion strain due to temperature change during the ASR measurement was neglected in equation (3). This equation, which provides a basis for the ASR stress measurement method, suggests that the anelastic strain depends on in-situ stress tensor components, the pore pressure and the compliances of both deformation modes. Therefore, if the material behaviors $[\operatorname{Jas}(t), \operatorname{Jav}(t)]$ and the pore pressure $p_{0}$ are known, the six components of in-situ stress, i.e., three-dimensional stress tensor can be obtained by measuring the anelastic normal strains in at least six independent directions.

For isotropic viscoelastic materials, the orientations of the three principal in-situ stresses coincide with the orientations of the three principal anelastic strains. Thus, the orientations of the three-dimensional principal in-situ stresses can be determined by calculating the orientations 
of principal strains based on the anelastic strain data measured in at least six independent directions. For a special case that the components of $S_{i j}$ and $e_{i j}(t)$ in equation (1) are principal stress and anelastic strain deviations, respectively, it can be easily obtained that ratios of the components of principal stress deviation are given by ratios of the components of principal anelastic strain deviation. That is, the relation between the ratios is given by:

$$
S_{i} / S_{j}=e_{i}(t) / e_{j}(t) \quad(i, j=1,2,3 ; i \neq j),
$$

where the values of principal stress deviation $S_{1,2,3}$ are given by subtracting the mean normal stress $\sigma_{m}$ from principal stresses $\sigma_{1,2,3}$, respectively, and the principal anelastic strain deviations $e_{1,2,3}(t)$ are similarly given. As a result, if the rock is thermally and mechanically isotropic, these principal orientations and the ratios of the components of principal stress deviation can be determined without knowing both the compliances as a function of time.

On the other hand, the magnitude of three-dimensional principal in-situ stresses is given by Matsuki and Takeuchi (1993):

$$
\sigma_{i}=e_{i}(t) / J a s(t)+e_{m}(t) / J a v(t)+p_{0} \quad(i=1,2,3) .
$$

Therefore, we can determine the in-situ stress magnitudes if both the compliances and the pore pressure are known.

Matsuki (1991) proposed a detailed procedure to determine the orientations and magnitudes of the three-dimensional in-situ stresses. He suggested that the two compliances $\operatorname{Jas}(t)$ and $\operatorname{Jav}(t)$ which are necessary to calculate values of the principal stresses, may be determined by measuring the anelastic strain recovery of the same core sample after it was tri-axially compressed and then, unloaded in laboratory conditions. Additionally, he emphasized that because of the dependence of the shear and volumetric mode compliances on the mean normal stress, previous loading level must be taken into consideration. However, because of this mean stress dependence, the calibration tests are usually very complex and require a sufficient number of specimens for the iterative method, since the stress level of the previous loading is not always equal to that of the real in-situ stress. In other words, if the stress conditions used in the calibration test differ significantly from the stress value being determined, the calibration test must be repeated until the applied and determined stresses become approximately equal to each other.

In general, it is impossible to begin anelastic strain measurements immediately after stress release; some time delay $\left(t_{0}\right)$ is obviously unavoidable. However, according to Matsuki (1992a), the method described above can be applied if only the compliances used were determined for the same time that elapsed from $t_{0}$. In order to shorten the time delay caused by core sample transportation, the ASR test should be carried out in an on-site laboratory.

\subsection{Rock Materials from TCDP Hole-A and Preparation of Specimens}

The core samples used in this study were taken from three depths of 592,1112, and $1755 \mathrm{~m}$ in the main Hole-A of the scientific deep drilling project TCDP. The drilling site is located in 
the vicinity of Taichung city in the central region of western Taiwan. In this main drilling hole all cores were continuously retrieved from a 500-m depth down to the maximum drilled depth of $2003 \mathrm{~m}$. According to Yeh et al. (2007), downward lithology column of Hole-A was identified as Cholan Formation (0 - 1027 m, early Pleistocene-Pliocene), Chinshui Shale Formation (1027 - 1290 m, early Pliocene), Kueichulin Formation (1290 - 1710 m, early Pliocene-late Miocene), and Cholan Formation (1710 - $2003 \mathrm{~m})$ again. Thus, the depths from which the cores were taken for ASR measurements are in the shallower Cholan Formation, Chinshui Shale Formation, and deeper Cholan Formation, respectively. The Chelungpu fault is an active fault, which slipped during the Chi-Chi earthquake that occurred in September 1999 which is approximately 5 years before the drilling of Hole-A and the ASR experiments. In the depth range of Chinshui Shale Formation or around the boundary between Chinshui Shale and Kueichulin Formations, which was considered to be the possible depth range from teleseismic data of the earthquake, four fault zones were encountered in the depth range from 1111 to $1241 \mathrm{~m}$. No certain scientific evidence(s) to identify which fault slipped during the earthquake has been obtained yet. However, many scientists believe that the fault zone located around $1111 \mathrm{~m}$ (FZA1111) is the most likely candidate of the earthquake faults the four fault zones (Song et al. 2007; Yeh et al. 2007). A core sample taken from $1112 \mathrm{~m}$ located within the FZA1111, but at its deeper portion. The other two core samples used in this study located far from the fault zone. The core from $1112 \mathrm{~m}$ is siltstone, the others are sandstone. The drill cores were not oriented by drilling tools; but their orientations were determined by the down dip orientation of the formation which is known.

Hereunder, we describe the actual experimental application for the TCDP to illustrate techniques used to prepare specimens for the ASR measurement for limited cases of core samples retrieved from a deep drilling well. In the TCDP, drilled cores were cut, caught then lifted from depth up to the surface using a wire-line technique. The total length of cores retrieved every time one was lifted up was 2 to $3 \mathrm{~m}$. As soon as possible after a core at the target depth was lifted up, a homogeneous and crack-free core of appropriate length was selected in order to prepare a specimen for the ASR measurement. To shorten the time elapsed from the stress release by drilling to the beginning of the ASR measurement, the deeper part of the core was selected. However, the deepest $8 \mathrm{~cm}$ from the bottom, approximately equal to the diameter of the core, was deliberately rejected given that stress in the bottom part might not be completely released.

We designed two methods preparing the specimen for ASR measurement shown in Figs. 1a - c (denote it as Method A) and Figs. 1d - e (Method B), respectively. An advantage and two disadvantages of Method B are: i) that one does not need to cut the core; ii) there may be some influences of drilling forces since the strain measurements are conducted on the cylindrical core surface; and iii) strain measured by the gauges on the cylindrical core surface except in the direction parallel to the core axis is not in a single direction. We prepared the specimens of 592- and 1175-m depths by Method A, but the specimen of 1112-m depth by Method B in order to preserve the core as being non-destroyed because it was located in the fault zone.

As shown in Fig. 1a, the selected core was cut in orientations with respect to local X, Y, and $\mathrm{Z}$ axes. The $\mathrm{Z}$ axis was parallel to the core axis and the $\mathrm{X}$ and $\mathrm{Y}$ axes were properly defined by referring to the down dip orientation of the formation. The flat surfaces of the three 
planes cut perpendicularly to each other were grinded by using sandpaper to make them smooth. In the humidity conditions of the on-site laboratory, the surfaces of the specimens quickly dried, attaining an air-dry state, while lines were being drawn on the specimens to determine the location and orientation of strain gauges to be glued onto them. Three cross-type wire strain gauges were mounted onto each of the three perpendicular planes, i.e., for each of the nine directions two strain gauges were used (cf. Fig. 1b). The type of strain gauges used in this study was of electrical resistance $120 \Omega$ with a 10 -mm effective length.

Regarding specimen preparation via Method B, we directly glued the strain gauges on the cylindrical core surface following the determination of locations and directions for gluing them. If the effects due to curvature of the surface are negligible, the nine directions of the strain measurements are $\mathrm{X}$ (its direction cosines are $1,0,0), \mathrm{Y}(0,1,0), \mathrm{Z}(0,0,1), \mathrm{XY}(0.707,0.707,0)$, -XY (-0.707, 0.707, 0), YZ (0, 0.707, 0.707), -YZ (0, -0.707, 0.707), ZX (0.707, 0, 0.707), and $-\mathrm{ZX}(-0.707,0,0.707)$. The directions of strain measurement and total number of gauges glued

(a)

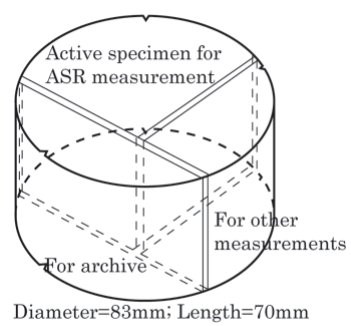

(d) (b)

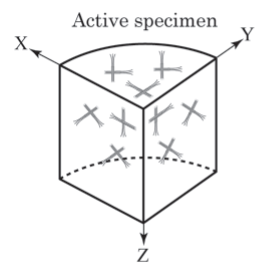

(c)

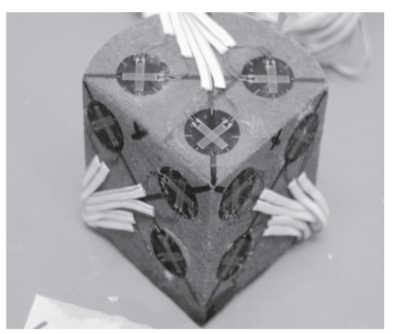

(e)

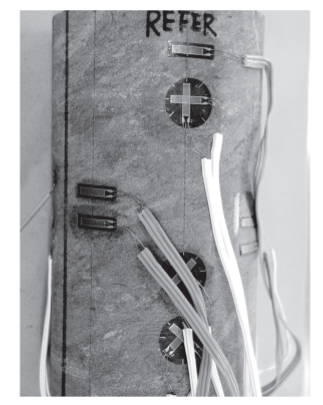

Fig. 1. Schematic illustrations of preparation of ASR specimen by Method A (a - c) and Method B (d - e). (a) The layout of specimen cut from a drill core. (b) The X, Y, Z axes of a local coordinate system and the layout of the strain gauges glued on the flat surfaces of the cut specimen. (c) An example of the cut specimen used for ASR test. (d) The layout of the strain gauges glued on the cylindrical surface of the non-cut core specimen. (e) An example of the non-cut core specimen used for ASR test. 
on one specimen are the same as that of Method A.

To avoid the influence of electrical resistance change of the lead wires of the gauges due to room temperature variation at the on-site laboratory, three-wire gauges and a corresponding bridge circuit were employed. The pictures in Figs. 1c and e show two examples of the specimens with strain gauges prepared via methods A and B, respectively, after ASR measurements.

Finally, we jacketed the specimens to prevent any changes of the pore water content during the measurement period of several days or weeks. In the case of Method A, the specimen was immersed in mixed silicone rubber of two-liquid type after wrapping the specimen in vinyl sacks. However, in the case of Method B, we put the specimen into a long aluminum sack and sealed it.

\subsection{The Anelastic Strain Measurement System}

The apparatus used for the ASR measurements is shown in Fig. 2. Because the data logger has 60 channels for strain measurement, three active specimens, on which 18 gauges were glued as shown in Fig. 1b or d, can be simultaneously measured. In addition, strain data from a dummy sandstone specimen, which does not undergo any deformation except thermal expansion, for monitoring the drift of the system, were acquired. Since we had to prepare the dummy specimen before the cores for active specimens were retrieved, and we did not have reliable information about the lithology of the cores beforehand, we prepared the dummy specimen using a fine-grained sandstone taken from Tanabe Formation (Miocene, in the Kii Peninsula, Japan). Although, no doubt, it would have been better to use the same rock material as that undergoing the anelastic strain recovery, the lithology of the dummy specimen is not important if the temperature is kept at a constant. All the specimens were placed in a constant

(a)

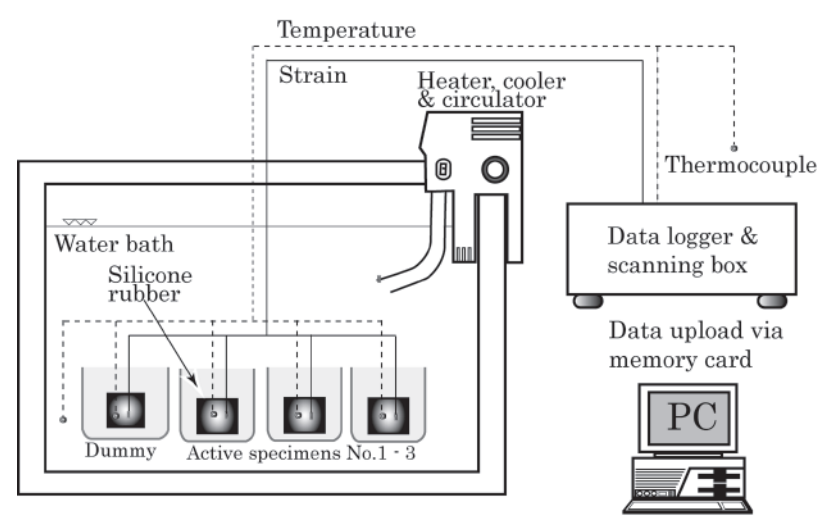

(b)

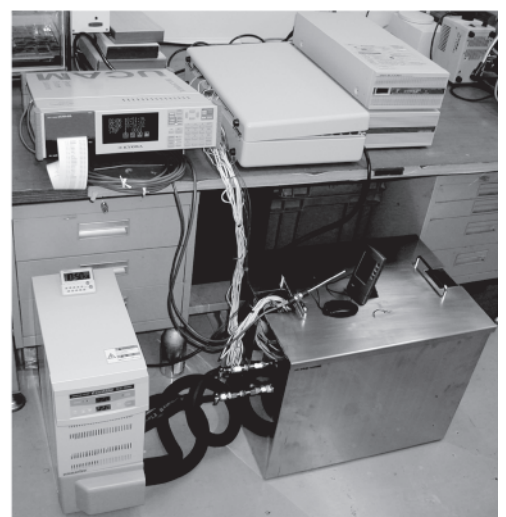

Fig. 2. Schematic diagram (a) and picture (b) of an anelastic strain measurement system. 
temperature chamber filled with tap water, controlled by a heater/cooler containing a water circulation system and a regulator. In this apparatus, the required or target constant temperature was set at a temperature near to room temperature, since large temperature changes before or after putting the specimens into the chamber must be avoided.

The strain gauges and two high-resolution thermometers (one measuring water temperature and one measuring room temperature) and several thermocouples were directly connected to a data logger with a 16-bit A/D converter. Digital strain and temperature data were recorded every 10 minutes. It took less than 1 hour to elevate the core from the depth to the surface, 2 hours to finish the on-site core sample handling including the procedures to clean the cores, draw lines to delineate the down dip orientation, and take pictures and preliminary descriptions. Finally, 2 hours were required to prepare the specimens and set them in the apparatus. For example, the strain measurement on the 592-m depth specimen began about 5 hours after the extraction of the core and stress release. In general, the anelastic strain recovery takes several weeks or several months after in-situ stress release. However, the whole anelastic strain recovery curve (from stress release to full recovery of the time-dependent non-reversible strain) is not necessary for stress analysis. That is, a part of the strain recovery curve is sufficient if only the stable strain recovery curve was obtained and the strain value reached a high enough level to assure satisfactory measurement accuracy. Therefore, a measurement session of about one week duration is in general sufficient for ASR measurement.

\section{THE DETERMINATION OF ORIENTATIONS AND ESTIMATION OF MAGNI- TUDES OF THREE-DIMENSIONAL STRESS BY THE ASR METHOD}

\subsection{An Example of the Anelastic Strain Curve}

As an example, measurement results of anelastic strain recovery of the specimen taken from a depth of 592-m are shown in Fig. 3. The capital letters beside the curves show the measurement directions mentioned above. The duration of the measurement for this specimen was approximately five weeks. Lack of data in a range of about 530 - 570 hours was due to memory capacity overload. During the experiment, the thermostatic chamber worked correctly; the temperature change was controlled to less than $\pm 0.1^{\circ} \mathrm{C}$. In addition, the acquired strain data from the dummy specimen shows that the drift of the measurement system was very small against the anelastic strain of the active specimen, especially in a time range of less than about 600 hours and can be neglected. For example, drift at around 500 hours was about 8 microstrains which corresponds to about 2 percent of mean value of the measured anelastic normal strains of the active specimen. Therefore, it is believed that the anelastic strain data were correctly measured in a quantitative sense at least for the former part until about 530 hours. Thus, the analysis of the principal strain etc. was carried out only using data of the elapsed time range from 0 to approximately 500 hours.

From Fig. 3, it is obvious that the anelastic strains in all directions of the active specimen were extensions; and all the curves were smooth and had a similar variation tendency as time increased. It can be said that anelastic strain recovery in all directions continued for a long 


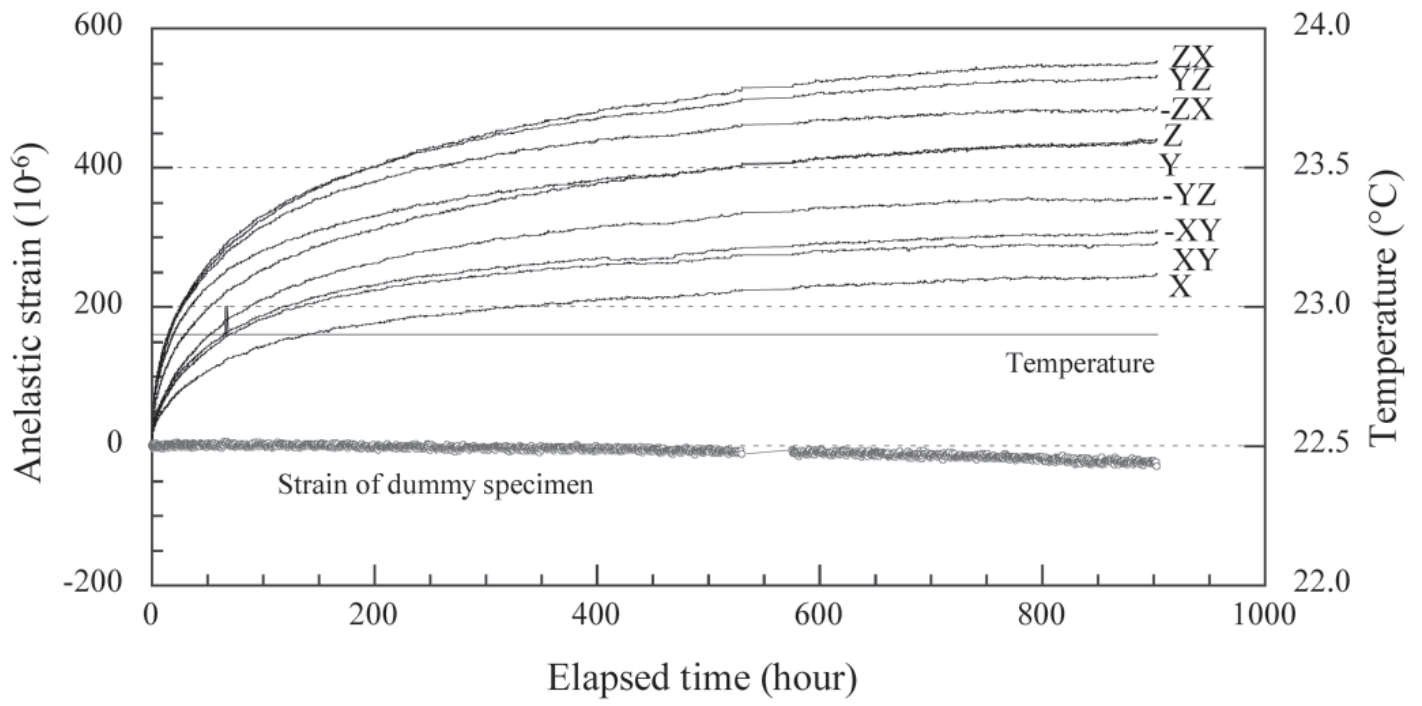

Fig. 3. Anelastic normal strain recovery curves of a sandstone specimen taken from the depth of $592 \mathrm{~m}$. The capital letters beside the curve show the measurement directions. Temperature was kept at $22.9 \pm 0.1^{\circ} \mathrm{C}$ during the measurement. Dummy specimen which did not undergo any deformation except thermal expansion was used for monitoring the drift of the strain measurement system.

period, although the rate of strain recovery decreased with time. The magnitude of strains in various directions, continuously measured for three weeks (504 hours) or more, achieved about 200 - 500 microstrains. For the measurement accuracy of the system used, this level of anelastic strain was sufficiently high and the data could be used for a three-dimensional analysis.

Of course, the magnitude of the anelastic strain depends on the duration of continuous measurement, the magnitude of in-situ stress, and anelastic strain recovery compliances of the rock material. In general, anelastic strain is less than the elastic strain accompanying stress release. Consequently, the ASR method is obviously suited to cases of high stress level, i.e., large depth and/or the soft rock materials of which the compliances are relatively larger, given one's viewpoint, to ensure the measurement accuracy of the strain.

\subsection{Determination of Orientations of Three-Dimensional In-Situ Stress}

From the measured anelastic normal strains in nine directions, including six independent directions, the anelastic strain tensor was calculated using least squares analysis. The calculated three principal strain components $\varepsilon_{1,2,3}(t)$ and the mean normal strain $e_{m}(t)$ of the specimen taken from a 592-m depth are shown in Fig. 4. Furthermore, relations between the three prin- 
cipal anelastic strain deviations $e_{1,2,3}(t)$, the ratio of the intermediate principal strain deviation to the major principal strain deviation $e_{2}(t) / e_{1}(t)$, the ratio of minor principal strain deviation to the major principal strain deviation $e_{3}(t) / e_{1}(t)$, and elapsed time $t$, respectively, were determined by using the same analysis procedure as described by Matsuki and Takeuchi (1993). Using a dataset of the ratios of the principal strain deviations for an arbitrary elapsed time, a dataset of the three orientations of the principal strains corresponding to time can be determined. Thus, an orientation data series of the three principal strains according to the elapsed time was obtained. The calculated orientations corresponding to the local coordinate system and their variation as elapsed time increased are shown in Fig. 5. At an early stage in the whole measurement period, the determined orientations of the principal strains scattered significantly because the ratios of the deviations were unstable when the maximum component of principal strain deviation, i.e., the denominator for calculating the ratios, was small. Consequently, the average of plunges and trends of the three principal strain orientations were calculated using data that didn't include this initial phase which corresponded to about one-tenth of the whole measurement period. According to Matsuki (1991), the orientations of the principal anelastic

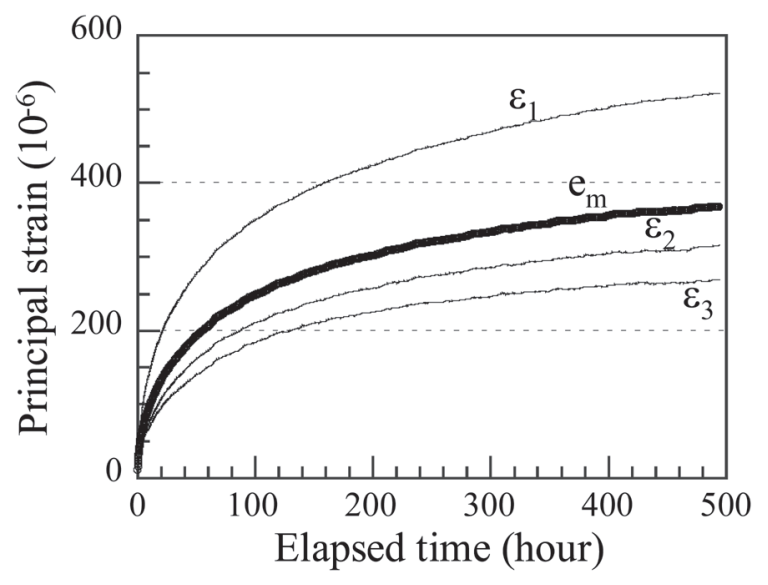

Fig. 4. Three principal anelastic strains and mean constant strain versus elapsed time. Notice that part of strain curves corresponding to a time range from about 500 to 900 hours in Fig. 4 was deleted because of lack of data in the range of about $530-570$ hours due to a lack of data logger memory capacity.

Fig. 5. Calculated orientations with respect to the local coordinate system and their variation as elapsed time increases.

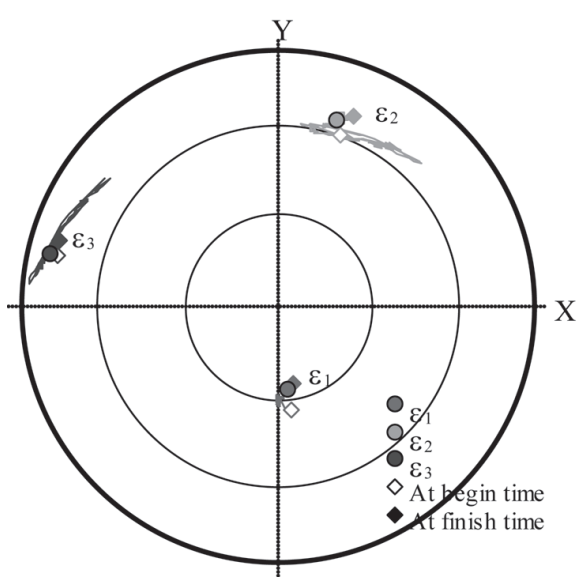


strains are the same as the orientations of the principal in-situ stresses.

The orientations of the three principal strains/stresses determined based on the results of the ASR measurements for the three depths are shown in lower hemisphere stereo projection (Fig. 6) corresponding to the global coordinate system by means of the equal area method. At the 592- and 1112-m depths, the orientation of the maximum in-situ stress $\left(\sigma_{l}\right)$ is nearly vertical and the orientation of the minimum stress $\left(\sigma_{3}\right)$ is approximately horizontal and the same as the down dip orientation of the sedimentary formations. That is, at a shallower depth located in the hanging wall of the active fault zone or just within the fault zone which slipped recently, the stress state showed the relatively distinct features of gravitational stress. It can be considered that such a stress regime is reasonable because slipping of the fault released the influence of tectonic stress. However, at a depth of $1755 \mathrm{~m}$ beneath the fault zone, the major stress is nearly in the down dip direction consistent with plate motion approximately; and the stress state represents features of tectonic stress.

\subsection{Estimation of Magnitude of Three-Dimensional Principal Stresses}

As mentioned in 2.1, in order to determine correctly the magnitude of the three principal in-situ stresses, the two anelastic strain recovery compliances [Jas $(t)$ and $\operatorname{Jav}(t)]$ of shear mode and of volumetric mode, respectively, should be examined based on laboratory tests of anelastic strain recovery. However, these calibration tests are very complex and require a great deal of time and effort, since the compliances depend on mean normal stress level. When the ratio of $\operatorname{Jas}(t)$ and $\operatorname{Jav}(t)$ is given as a constant by assuming that the compliances are similar to each other, the ratios among $\sigma_{i}-p_{0}(\mathrm{i}=1,2,3) \mathrm{in} \mathrm{Eq}$. (5) can be determined without knowing the compliances as a function of time. Accordingly, by giving the value of the vertical stress based on the assumption that it is given by overburden stress, all magnitudes of the three principal stresses can be determined. Therefore, this simpler method was employed in the present study to estimate the magnitudes of the principal stresses.

According to results of laboratory experimental tests by Matsuki (1992b), both the compliances have similar behavior to each other. In addition, the ratio of the $J a s(t)$ and $J a v(t)$ can be considered to be a constant at arbitrary time for a certain rock type. He tested eight types of rock including sandstone, tuff and granite. The results showed that the ratio depends on rock type, but varied in a relative narrow range within about $1-3$; and the average value of the ratios from the tested rocks was about 1.9. Therefore, it can be considered appropriate to assume the ratio to be a constant for simplifying Eq. (5). When the ratio of the $J a s(t)$ and $J a v(t)$ is given as a constant $c=\operatorname{Jas}(t) / \operatorname{Jav}(t)$, Eq. (5) can be given as follows:

$$
\sigma_{\mathrm{i}}=\left[e_{i}(t) / c+e_{m}(t)\right] / J a v(t)+p_{0} \quad(i=1,2,3) .
$$

Because vertical in-situ stress $\sigma_{v}$ can be estimated to be equal to the bulk density-related gravitational overburden stress, we can calculate the $\operatorname{Jav}(t)$ without laboratory calibration testing by using a relation between $\sigma_{v}$ and $\operatorname{Jav}(t)$. Concretely, based on the determined orientations of three-dimensional stress, $\sigma_{v}$ is given as follows: 

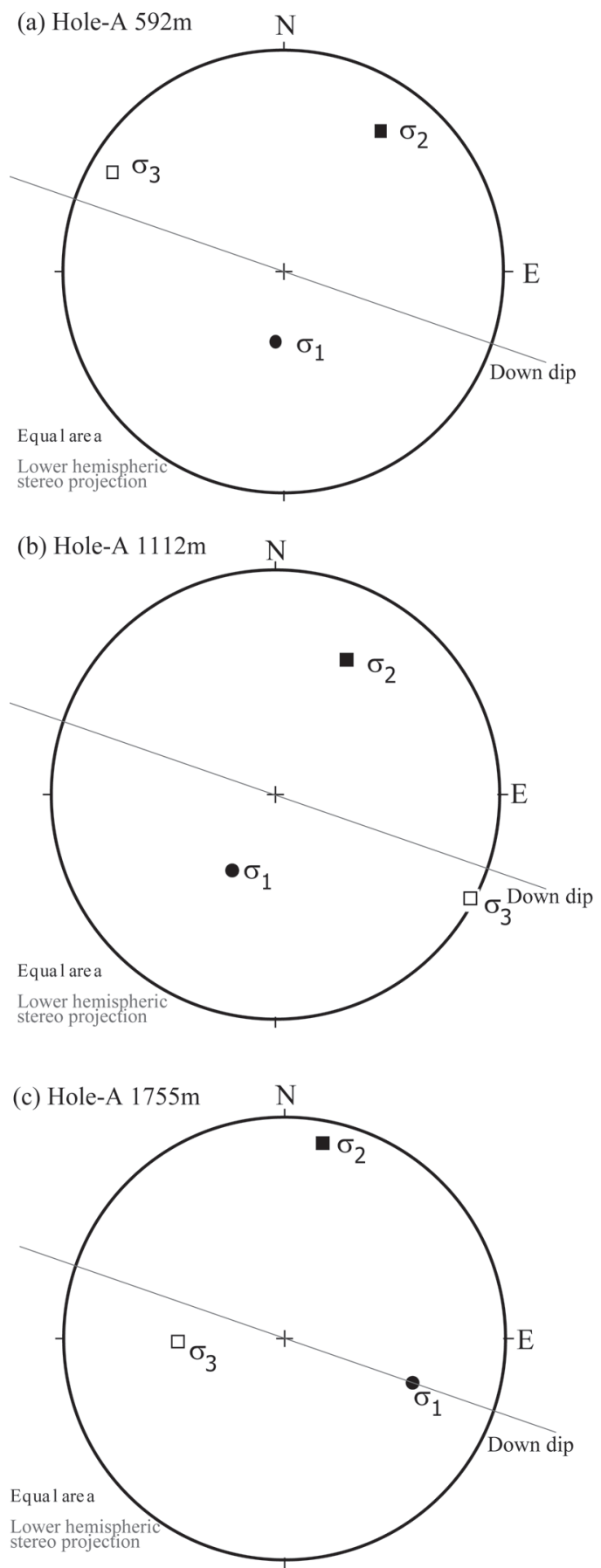

Fig. 6. Determined orientations of three-dimensional in-situ stress at the three depths. Straight line denoted as "Down dip"shows the orientation of the down dip of the formation. 


$$
\sigma_{v}=l_{p}^{2} \sigma_{1}+m_{p}^{2} \sigma_{2}+n_{p}{ }^{2} \sigma_{3}
$$

where $l_{p}, m_{p}, n_{p}$ are the direction cosines of vertical vector with respect to the three coordinate axes of the principal stresses. By combining the equations (6) and (7), the relation between $\sigma_{v}$ and $J a v(t)$ was derived:

$$
\sigma_{v}=\left\{\left[l_{p}{ }^{2} e_{1}(t)+m_{p}{ }^{2} e_{2}(t)+n_{p}{ }^{2} e_{3}(t)\right] / c+e_{m}(t)\right\} / J a v(t)+p_{0} .
$$

Therefore, we can determine the $\operatorname{Jav}(t)$ from the equation based on the measured values of anelastic strain $e_{i}(t), e_{m}(t)$ for the time when the ASR test finished, and given pore pressure $p_{0}$ (assumed to be hydrostatic pressure). Accordingly, it is possible to predict the magnitudes of three principal stresses by using Eq. (6) based on estimated compliances, anelastic strain, etc. For determining input parameters in the question, we also made the following assumptions: i) average density of the formations above the depth at where the ASR measurements were conducted is equal to $2.4 \mathrm{~g} \mathrm{~cm}^{-3}$; ii) the ground water level is at the ground surface; and iii) water density is equal to $1.0 \mathrm{~g} \mathrm{~cm}^{-3}$. Thus, the overburden stress $\sigma_{v}$ and the pore pressure $p_{0}$ at the three depths could be estimated. For example, the overburden stress and the pore pressure at the 592-m depth were estimated to be equal to 14 and $6 \mathrm{MPa}$, respectively. As a result, the magnitude of major principal stress at the 592-m depth estimated on the basis of the overburden stress and pore pressure was $15 \mathrm{MPa}$, the intermediate stress was $13 \mathrm{MPa}$, and the minor stress was $12 \mathrm{MPa}$. Consequently, stress magnitudes predicted at all three depths are shown in Table 1.

\section{SUMMARY AND FUTURE WORK}

Table 1. Preliminary results of the magnitudes of three principal stresses pre-

\begin{tabular}{|c|c|c|c|c|c|c|}
\hline & $\begin{array}{l}\text { Depth } \\
(\mathrm{m}) \\
\end{array}$ & $\begin{array}{c}\text { Normal stress in } \\
\text { vertical direction }^{* 1} \\
(\mathrm{MPa})\end{array}$ & $\begin{array}{c}\text { Pore } \\
\text { pressure }^{* 2} \\
(\mathrm{MPa}) \\
\end{array}$ & $\begin{array}{c}\text { Major principal } \\
\text { stress }^{* 3} \\
(\mathrm{MPa}) \\
\end{array}$ & $\begin{array}{c}\text { Intermediate } \\
\text { principal stress }^{* 3} \\
(\mathrm{MPa})\end{array}$ & $\begin{array}{c}\text { Minor principal } \\
\text { stress }^{* 3} \\
(\mathrm{MPa}) \\
\end{array}$ \\
\hline & 592 & 14 & 6 & 15 & 13 & 12 \\
\hline & 1112 & 26 & 11 & 28 & 24 & 19 \\
\hline & 1755 & 42 & 18 & 54 & 46 & 34 \\
\hline${ }^{*} 1$ & \multicolumn{6}{|c|}{ Estimated by $\sigma_{\mathrm{v}}=\rho_{\text {Ave }}$ gh based on the assumption of $\rho_{\text {Ave }}=2.4 \mathrm{~g} / \mathrm{cm}^{3}$. } \\
\hline$* 2$ & \multicolumn{6}{|c|}{$\begin{array}{l}\text { Based on the assumption that pore pressure is equal to hydraulic static pressure, and the ground } \\
\text { water level is at the ground surface. }\end{array}$} \\
\hline
\end{tabular}
dicted from ASR measurements. 
In order to understand the features of in-situ rock stress change at different depths above, within, and beneath the Chelungpu fault after the Chi-Chi earthquake and to acquire skills for core-based stress measurement techniques, we employed the anelastic strain recovery (ASR) technique to determine the orientations and to estimate the magnitudes of present threedimensional principal stresses by using core samples retrieved from Taiwan Chelungpu-fault Drilling Project (TCDP) main Hole-A. In this paper, we first outline the ASR method and detail the procedures of specimen preparation and stress analysis applied to the TCDP. Then, we show the measured anelastic strain data and preliminary results of determined orientations and estimated magnitudes of the principal stresses.

The core specimens used were two sandstones taken from depths of 592 and $1755 \mathrm{~m}$ and a siltstone from $1112 \mathrm{~m}$ in TCDP Hole-A. The anelastic strains of the specimens in nine directions, including six independent directions, were measured using wire strain gauges after having retrieved the core from the target depth. Acquired anelastic strains were extensions; they reached several hundred microstrains which is a level high enough to ensure satisfactory measurement accuracy. These strains were used for a three-dimensional analysis resulting in determination of the orientations and prediction of the magnitudes of the principal in-situ stresses. Preliminary measurement results of the orientations of the principal stresses showed the stress distribution in the TCDP hole might be influenced by the Chelungpu fault rupture. In addition, the results obtained can be considered as valid. Consequently, it can be said that anelastic strain recovery measurement is well suited to the task of directly determining the orientations of principal in-situ stresses and to estimating the magnitude of the stresses at large/great depth.

In order to improve stress measurement techniques, experimental future work should focus on: i) conducting laboratory calibration tests to obtain the anelastic strain compliances and understand their behavior; ii) examining the anisotropy of ASR and estimate its influence for the application of the isotropy model; and iii) compiling ASR data for Hole-A and Hole-B. Additionally, in order to investigate correlations between the stress regime and the Chelungpu fault and its rupture inducing the Chi-Chi earthquake, future studies are important such as: i) compiling the ASR results with other stress information via hydraulic fracturing tests and breakout analyses, and conventional stress data in the same survey region; and ii) building an appropriate model to explain the current stress state and to infer stress change induced by the fault rupturing.

Acknowledgements The authors acknowledge Li-Sheng Tsai, Zheng-Wang Chen, and onsite assistants of National Central University, National Taiwan University for their kind help in the ASR measurements. We also thank two reviewers for their useful comments. This work was supported by Grants-in-Aid for Scientific Research (Scientific Research C: 16540392) of the Japan Society for the Promotion of Science (JSPS), Japan.

\section{REFERENCES}

Kao, H., and W. P. Chen, 2000: The Chi-Chi earthquake sequence: active out-of-sequence thrust faulting in Taiwan. Science, 288, 2346-2349. 
Lin, W., M. Kwasniewski, T. Imamura, and K. Matsuki, 2006: Determination of three-dimensional in-situ stresses from anelastic strain recovery measurement of cores at great depth. Tectonophysics, 426, 221-238.

Ma, K. F., T. R. Song, S. J. Lee, and H. I. Wu, 2000: Spatial slip distribution of the September 21, 1999, Chi-Chi, Taiwan earthquake $\left(\mathrm{M}_{\mathrm{w}}\right.$ 7.6)-Inverted from teleseismic data. Geophys. Res. Lett., 27, 3417-3420.

Matsuki, K., 1991: Three-dimensional in-situ stress measurement with anelastic strain recovery of a rock core. In: Wittke, W. (Ed.), Proc. $7^{\text {th }}$ Int. Congr. Rock Mech., Aachen, 1, 557560.

Matsuki, K., 1992a. Theoretical examination of the method for measuring three-dimensional in-situ stresses with anelastic strain recovery of rock core. J. Min. Material Proc. Inst. Japan, 108, 41-45. (in Japanese)

Matsuki, K., 1992b: Fundamental study on stress measurement at great depth by core-based methods, 1991 Fiscal Year Accomplishment Report for Supporting by Grant-In-Aid for Scientific Research (C: 02805076), 95 pp. (in Japanese)

Matsuki, K., and K. Takeuchi, 1993: Three-dimensional in-situ stress determination by anelastic strain recovery of a rock core. Int. J. Rock Mech. Min. Sci. \& Geomech., 30, 10191022.

Mori, J., H. Ito, and C. Y. Wang, 2002: Chelungpu fault drilling could resolve seismological issues. EOS Trans. AGU, 83, 255 pp.

Song, S. R., L. W. Kuo, E. C. Yeh, C. Y. Wang, J. H. Hung, and K. F. Ma, 2007: Characteristics of the lithology, fault-related rocks and fault zone structures in TCDP Hole-A. Terr. Atmos. Ocean. Sci., 18, 243-269, doi: 10.3319/TAO.2007.18.2.243(TCDP).

Teufel, L. W., 1983: Determination of in-situ stress from anelastic strain recovery measurements of oriented core. SPE paper 11649, SPE/DOE Symposium on Low Permeability, Denver, CO, 421-430.

Voight, B., 1968: Determination of the virgin state of stress in the vicinity of a borehole from measurements of a partial anelastic strain tensor in drill cores. Felsmech. Ingenieurgeol., 6, 201-215.

Yeh, E. C., H. Sone, T. Nakaya, K. H. Ian, S. R. Song, J. H. Hung, W. Lin, T. Hirono, C. Y. Wang, K. F. Ma, W. Soh, and M. Kinoshita, 2007: Core description and characteristics of fault zones from Hole-A of the Taiwan Chelungpu-fault Drilling Project. Terr. Atmos. Ocean. Sci., 18, 327-357, doi: 10.3319/TAO.2007.18.2.327(TCDP).

Lin, W., E. C. Yeh, H. Ito, T. Hirono, W. Soh, C. Y. Wang, K. F. Ma, J. H. Hung, and S. R. Song, 2007: Preliminary results of stress measurement using drill cores of TCDP Hole-A: an application of anelastic strain recovery method to three-dimensional in-situ stress determination. Terr. Atmos. Ocean. Sci., 18, 379-393, doi: 10.3319/TAO.2007.18.2. 379(TCDP). 